\title{
Nasopharyngeal Cancer pN2 TNM Finding v7
}

National Cancer Institute

\section{Source}

National Cancer Institute. Nasopharyngeal Cancer pN2 TNM Finding v7. NCI Thesaurus. Code C88973.

Nasopharyngeal cancer with bilateral metastasis in cervical lymph node(s), $6 \mathrm{~cm}$ or less in greatest dimension, above the supraclavicular fossa. Midline nodes are considered ipsilateral nodes. (from AJCC 7th Ed.) 